\title{
Factors associated with aorto-ostial stent coverage during intravascular ultrasound-guided percutaneous coronary intervention to severely narrowed non-ostial right coronary artery lesions
}

\author{
Masataka Narita, Kenichi Sakakura, Yousuke Taniguchi, Kei Yamamoto, Takunori Tsukui, Masaru Seguchi, \\ Hiroyuki Jinnouchi, Hiroshi Wada, Hideo Fujita
}

Division of Cardiovascular Medicine, Saitama Medical Center, Jichi Medical University, Saitama, Japan

Adv Interv Cardiol 2021; 17, 2 (64): 163-169

DOI: https://doi.org/10.5114/aic.2021.107494

\begin{abstract}
A b stract
Introduction: In percutaneous coronary intervention ( $\mathrm{PCI}$ ) to atherosclerotic lesions in the right coronary artery (RCA), coronary artery dissection in the ostium of the RCA is a rare but fatal complication. Stent implantation to the ostium of RCA may be selected for the prevention of aorto-ostial dissection.

Aim: To find factors associated with aorto-ostial stent coverage to mild to moderate ostial stenosis during the treatment of severely narrowed non-ostial RCA lesions.

Material and methods: The primary interest was to find factors associated with ostial stent coverage using multivariate regression analysis. We included 236 patients who underwent intravascular ultrasound (IVUS)-guided PCI to severely narrowed RCA lesions with mild to moderate ostial stenosis, and divided those into the ostial-coverage group $(n=52)$ and the non-coverage group $(n=184)$.

Results: The prevalence of continuous ostial plaque detected by intravascular ultrasound (IVUS) was significantly greater in the ostial-coverage group (84.6\%) than in the non-coverage group $(52.9 \%)(p<0.001)$. Multivariate logistic regression analysis revealed that continuous ostial plaque detected by IVUS (OR $=5.398,95 \% \mathrm{Cl}: 2.322-12.553, p<0.001)$ was significantly associated with ostial stent coverage after controlling confounding factors. Ischaemia-driven target vessel revascularization was less frequently observed in the ostial-coverage group than in the non-coverage group, without reaching statistical significance $(p=0.069)$.

Conclusions: Continuous ostial plaque detected by IVUS was significantly associated with ostial stent coverage to the mild to moderate stenosis when PCI to non-ostial, severely narrowed RCA lesions was performed. The use of IVUS may enhance the safety but may increase the total stent length in PCI to RCA.
\end{abstract}

Key words: intravascular ultrasound, coronary imaging, target vessel revascularization.

S u m m a ry

In percutaneous coronary intervention $(\mathrm{PCI})$ to atherosclerotic lesions in the right coronary artery (RCA), coronary artery dissection in the ostium of the RCA is a rare but fatal complication. We investigated factors associated with aorto-ostial stent coverage to mild to moderate ostial stenosis during the treatment of severely narrowed, non-ostial RCA lesions. The multivariate logistic regression analysis revealed that continuous ostial plaque detected by intravascular ultrasound (IVUS) was significantly associated with ostial stent coverage, and ischaemia-driven target vessel revascularization was less frequently observed in the ostial-coverage group than in the non-coverage group. The use of IVUS may enhance the safety but may increase the total stent length in PCI to RCA.

\section{Introduction}

In percutaneous coronary intervention ( $\mathrm{PCl})$ to atherosclerotic lesions in the right coronary artery (RCA), cor- onary artery dissection in the ostium of the RCA is a rare but fatal complication, because dissection can extend to the ascending aorta retrogradely [1-3]. Stent implantation

Corresponding author:

Kenichi Sakakura MD, Division of Cardiovascular Medicine, Saitama Medical Center, Jichi Medical University, Saitama, Japan,

phone: 81486472111, e-mail: ksakakura@jichi.ac.jp

Received: 19.01.2021, accepted: 15.05.2021. 
to the ostium of the RCA may be selected not only for the treatment of atherosclerotic lesions, but also for the prevention of aorto-ostial dissection $[1,4,5]$. Indeed, it is not uncommon to implant stents to non-severely narrowed ostial lesions following stent implantation to severely narrowed, non-ostial RCA lesions in the contemporary drug-eluting stent era. However, references regarding aorto-ostial stent coverage have been sparse in PCI to RCA.

\section{Aim}

The purpose of this study was to find factors associated with aorto-ostial stent coverage to mild to moderate stenosis during intravascular ultrasound (IVUS)-guided $\mathrm{PCl}$ of severely narrowed, non-ostial RCA lesions.

\section{Material and methods}

\section{Study lesions}

We reviewed consecutive $\mathrm{PCl}$ cases in the Saitama Medical Center, Jichi Medical University from 1 January 2017 to 31 December 2019. Inclusion criteria were (1) cases that underwent $\mathrm{PCI}$ to severely narrowed, non-ostial RCA stenosis ( $\geq 75 \%$ ), and ( 2 ) cases that had mild to moderate stenosis at the ostium of the RCA before $\mathrm{PCl}$. Exclusion criteria were (1) cases that had severe stenosis ( $\geq 75 \%$ ) at the ostium of the RCA before $\mathrm{PCl},(2)$ cases that did not have any stenosis (i.e. $0 \%$ stenosis) at the ostium of the RCA before $\mathrm{PCl},(3)$ cases that underwent stent-less $\mathrm{PCl}$, (4) cases in which PCl was unsuccessful, (5) cases that did not use IVUS, (6) cases in which IVUS data was not available for analysis, and (7) cases in which quantitative coronary angiography (QCA) was not available before stent implantation. We defined the ostium of RCA as $\leq 3 \mathrm{~mm}$ from the aorto-ostial border (4). The ostial-stent coverage was defined as stenting in the area of the ostium of RCA (i.e. $\leq 3 \mathrm{~mm}$ from the aorto-ostial border). The final study population was divided into the ostial-coverage group, which underwent stent implantation to the ostium of the $\mathrm{RCA}$, and the non-coverage group, which did not undergo stent implantation to the ostium of the RCA. Our primary interest was to find factors associated with ostial-stent coverage using multivariate logistic regression analysis. We also compared the clinical outcomes between the ostial-coverage group and the non-coverage group. In the follow-up analysis, the primary outcome was ischaemia-driven target vessel revascularization (TVR). We defined the follow-up duration ranged from the day of $\mathrm{PCl}$ until the date of ischaemia-driven TVR or the study end date (31 July 2020). This study was approved by the institutional review board (S20-076), and written informed consent was waived because of the retrospective study design.

\section{Definition}

Acute myocardial infarction (AMI) was defined based on the universal definition of myocardial infarction $[6,7]$.
ST-elevation myocardial infarction (STEMI) was diagnosed in the presence of new ST elevation at the J point in at least 2 contiguous leads $\geq 2 \mathrm{~mm}(0.2 \mathrm{mV})$ [8]. Hypertension was defined as medical treatment for hypertension or a history of hypertension before admission [9, 10]. Dyslipidaemia was defined as a total cholesterol level $\geq 220 \mathrm{mg} / \mathrm{dl}$, low-density lipoprotein cholesterol level $\geq 140 \mathrm{mg} / \mathrm{dl}$, medical treatment for dyslipidaemia, or a history of dyslipidaemia [11-13]. Diabetes mellitus was defined as a haemoglobin $A_{1 c}$ level $\geq 6.5 \%$ (as NGSP value), medical treatment for diabetes mellitus, or a history of diabetes mellitus [11]. We calculated the estimated glomerular filtration rate (eGFR) from the serum creatinine level, age, weight, and gender using the following formula: eGFR $=194 \times \mathrm{Cr}-1.094 \times$ age -0.287 (male), eGFR = 194 $\times \mathrm{Cr}-1.094 \times$ age $-0.287 \times 0.739$ (female) [14].

\section{Angiographical analysis}

Quantitative coronary angiography (QCA) parameters were measured using a cardiovascular angiography analysis system (QAngio XA 7.3, MEDIS Imaging Systems, Leiden, Netherlands) [15-17]. The values of minimum lumen diameter, percentage diameter stenosis, lesion length, and reference diameter were obtained from pre-procedural angiography. In cases of total occlusion such as STEMI or chronic total occlusion, QCA was performed from the image after balloon dilatation. Cases that did not have an appropriate angiographic image for QCA were excluded. In our catheter laboratory, the use of IVUS was encouraged during the study period. Continuous ostial plaque was defined as continuous plaque from the culprit lesion to the guide catheter or RCA ostium.

\section{Statistical analysis}

Data are shown as the mean \pm SD for normally distributed variables, median (interquartile range) for non-normally distributed variables, or percentage. The Kolmogorov-Smirnov test was performed to determine whether the continuous variables were normally distributed. Normally distributed continuous variables were compared between the groups using the unpaired Student's $t$-test. Otherwise, the continuous variables were compared using the Mann-Whitney $U$ test. Categorical variables were compared using a $\chi^{2}$ test. Event-free survival curves were constructed using the Kaplan-Meier method, and statistical differences between the curves were assessed by the log lank test. $P<0.05$ was considered statistically significant. We performed a multivariate logistic regression analyses to find factors associated with ostial-stent coverage. In this model, the ostial-stent coverage was adopted as a dependent variable. Variables that had significant differences $(p<0.05)$ between the ostial-coverage group and the non-coverage group were adopted as independent variables. When there were 2 or more similar 
variables, only 1 variable was entered into the multivariate logistic regression analysis to avoid multi-collinearity. The odds ratio (OR) and the 95\% confidence interval (CI) were also calculated. We analysed all data by SPSS ver. 24 for Windows (SPSS, Inc., Chicago, Illinois).

\section{Results}

During the study period, we had 810 patients who underwent $\mathrm{PCI}$ to the RCA lesions in our medical centre. We excluded 466 cases that had $\geq 75 \%$ stenosis or no stenosis at the RCA ostium by angiography. Of 344 cases that had mild to moderate stenosis at RCA ostium, 108 cases were excluded according to the exclusion criteria. The final study population was 236 patients, who were divided into the ostial-coverage group $(n=52)$ and the non-coverage group ( $n=184)$. A study flowchart is shown in Figure 1 . The median follow-up duration was 13 months.

The comparison of clinical characteristics between the ostial-coverage and non-coverage groups is shown in Table I. Clinical characteristics except age were comparable between the 2 groups. A comparison of lesion and procedural characteristics between the 2 groups is shown in Table II. Lesion length was significantly longer in the ostial-coverage group (32.1 $\mathrm{mm}(13.1-42.7 \mathrm{~mm})$ ) than in the non-coverage group (17.2 $\mathrm{mm}(10.3-31.1 \mathrm{~mm})$ ) $(p=0.012)$. The prevalence of chronic total occlusion lesion was significantly greater in the ostial-coverage group $(23.1 \%)$ than in the non-coverage group $(8.7 \%)$ $(p=0.008)$. The prevalence of continuous ostial plaque detected by IVUS was significantly greater in the ostial-

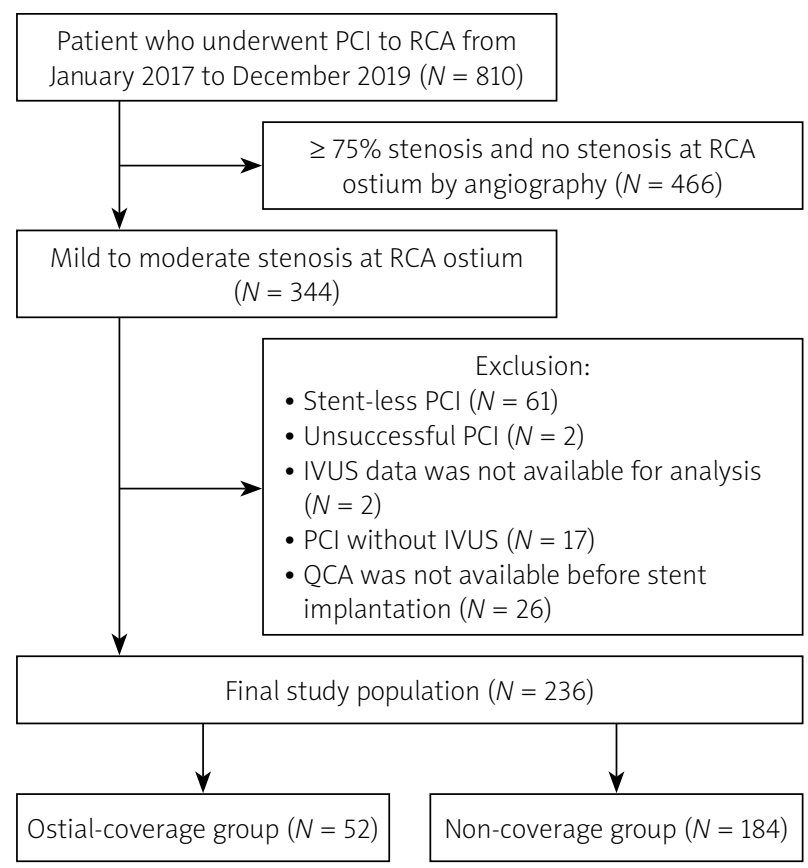

Figure 1. Study flowchart

$\mathrm{PCl}$ - percutaneous coronary intervention, RCA - right coronary artery, IVUS - intravascular ultrasound, QCA - quantitative coronary angiography. coverage group (84.6\%) than in the non-coverage group $(52.9 \%)(p<0.001)$. Rotational atherectomy was more frequently used in the ostial-coverage group (23.1\%) than in the non-coverage group (8.7\%) ( $p=0.008)$.

The multivariate logistic regression analysis performed to find factors associated with ostial stent coverage is shown in Table III. Continuous ostial plaque detected by IVUS (OR $=5.398,95 \% \mathrm{Cl}: 2.322-12.553, p<0.001)$ was significantly associated with ostial stent coverage and the use of Amplatz left $(\mathrm{AL})$ type guide catheter (vs. others: $\mathrm{OR}=0.403,95 \% \mathrm{Cl}: 0.187-0.868, p=0.02$ ) were inversely associated with ostial stent coverage. The Kaplan-Meier curves showed that ischaemia-driven TVR was less frequently observed in the ostial-coverage group than in the non-coverage group, without reaching statistical significance $(p=0.069)$.

\section{Discussion}

The present study included 236 cases that underwent stent implantation to severely narrowed, non-ostial RCA lesions, divided into an ostial-coverage group $(n=52)$ and a non-coverage group $(n=184)$. Ostial stent coverage was significantly associated with continuous ostial plaque detected by IVUS and was inversely associated with the use of an AL-type guide catheter in the multivariate logistic regression analysis. Kaplan-Meier curves revealed a trend that the ostial stent coverage was in-

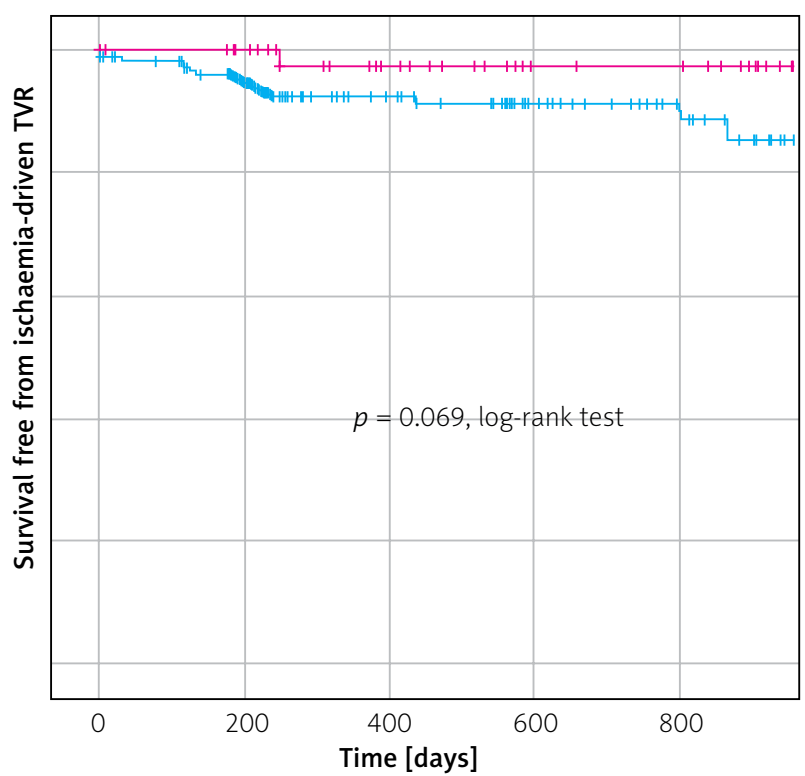

No. at risk

$\begin{array}{ccccc}\begin{array}{c}\text { Ostial-coverage } \\ 52\end{array} & 43 & 30 & 18 & 16 \\ \begin{array}{cccc}\text { Non-coverage } \\ 184\end{array} & 139 & 87 & 53 & 34 \\ & & & & \\ & & \text { Ostial-coverage } & \text { Non-coverage }\end{array}$

Figure 2. Kaplan-Meier curves describing survival free from ischaemia-driven target vessel revascularization 
Table I. Comparison of clinical characteristics between the ostial-stent and non-stent groups

\begin{tabular}{|c|c|c|c|c|}
\hline Patient characteristics & $\begin{array}{c}\text { All } \\
(n=236)\end{array}$ & $\begin{array}{l}\text { Ostial-coverage } \\
\quad(n=52)\end{array}$ & $\begin{array}{c}\text { Non-coverage } \\
(n=184)\end{array}$ & $P$-value \\
\hline Age [years] & $73.0(68.0-80.0)$ & $76.5(70.3-81.0)$ & $72.0(67.0-79.0)$ & 0.009 \\
\hline Men, $n(\%)$ & $181(76.7)$ & $38(73.1)$ & $143(77.7)$ & 0.465 \\
\hline Body mass index $\left[\mathrm{kg} / \mathrm{m}^{2}\right]$ & $23.4(22.0-25.4)(n=232)$ & $23.8(22.1-25.9)(n=51)$ & $23.3(21.8-25.4)(n=181)$ & 0.476 \\
\hline Hypertension, $n(\%)$ & $206(87.7)(n=235)$ & $43(82.7)(n=52)$ & $163(89.1)(n=183)$ & 0.235 \\
\hline Diabetes mellitus, $n$ (\%) & $13.6(58.1)(n=234)$ & $33(61.5)(n=52)$ & $104(57.1)(n=182)$ & 0.634 \\
\hline Dyslipidaemia, $n$ (\%) & $186(78.8)$ & $41(78.8)$ & $145(78.8)$ & 1.000 \\
\hline $\begin{array}{l}\text { Chronic kidney disease (GFR }<60 \mathrm{ml} / \\
\left.\mathrm{min} / 1.73 \mathrm{~m}^{2}\right)\end{array}$ & $117(49.6)$ & $21(51.9)$ & $90(48.9)$ & 0.755 \\
\hline Current smoking, $n(\%)$ & $50(21.9)(n=228)$ & $10(20.4)(n=49)$ & $40(22.3)(n=179)$ & 0.848 \\
\hline Previous myocardial infarction, $n$ (\%) & $60(25.5)(n=235)$ & $14(26.9)(n=52)$ & $46(25.1)(n=183)$ & 0.857 \\
\hline $\begin{array}{l}\text { Previous percutaneous coronary } \\
\text { intervention, } n(\%)\end{array}$ & $104(44.3)(n=235)$ & $24(46.2)(n=52)$ & $80(43.7)(n=183)$ & 0.755 \\
\hline $\begin{array}{l}\text { Previous coronary artery bypass } \\
\text { grafting, } n(\%)\end{array}$ & $14(6.0)(n=235)$ & $2(3.8)(n=52)$ & $12(6.6)(n=183)$ & 0.741 \\
\hline Left ventricular ejection fraction (\%) & $55.3(44.7-63.2)(n=213)$ & $56.7(47.7-66.4)(n=46)$ & $55.0(43.0-62.6)(n=167)$ & 0.133 \\
\hline
\end{tabular}

Data are expressed as the median (interquartile range) or number (percentage). Student's t-test or Mann-Whitney U test was used for continuous variables, and $\chi^{2}$ test was used for categorical variables.

versely associated with the occurrence of ischaemia-driven TVR.

We should discuss why continuous ostial plaque detected by IVUS was significantly associated with ostial stent coverage. First, because expert consensus documents have recommended that plaque burden should be less than $50 \%$ at the stent edge without lipid pool [18], we might have added another stent when the stent proximal edge was on the plaque that continued until the ostium of RCA. In fact, because the retrograde coronary artery dissection is the most catastrophic complication in $\mathrm{PCl}$ [19], we might take a conservative strategy to avoid the retrograde coronary-aorta dissection. Moreover, complete full-metal jacket strategy is known to be better than incomplete full-metal jacket strategy in $\mathrm{PCl}$ for diffuse RCA stenosis [20]. Yano et al. reported that the length of stent was not associated with long-term adverse events in IVUS-guided PCI using everolimus-eluting stents [21]. Therefore, we might not hesitate to place another stent to cover mild to moderate ostial RCA lesions, while long stent coverage poses a greater risk of long-term adverse events such as stent thrombosis especially in first-generation, drug-eluting stents [22].

We should also discuss why the AL-type guide catheter was inversely associated with ostial stent coverage. In general, the risk of coronary injury is considered to be greater in the AL-type guide catheters than in the Judkins type guide catheters $[23,24]$. However, our results were contradictory, which requires careful interpretation. When operators planned to perform aorto-ostial stenting before procedures, they might select Judkins-type guide catheters, because the Judkins type is technically easier for aorto-ostial stenting than the AL type. Furthermore, there were no cases that showed coronary injury caused by the guide catheter in our study population, partly because side holes on the guide catheter were available in all cases. Therefore, our results do not imply that the AL-type guide catheters have a protective effect to avoid aorto-ostial stenting.

The clinical implications of the present study should be noted. Because the mid-term, ischaemia-driven TVR tended to be less in the ostial-coverage group than in the non-coverage group, ostial stent coverage may be an option for mild to moderate stenosis in the RCA ostium, when $\mathrm{PCl}$ to a severely narrowed non-ostial RCA lesion is planned. Because a factor associated with aorto-ostial coverage was continuous ostial plaque detected by IVUS, the use of IVUS may increase the chance of aorto-ostial coverage as compared to PCI without IVUS. However, it is still unknown whether the use of IVUS might enhance the safety of PCI to RCA lesions or just increase the total length of stenting. Moreover, although IVUS had difficulty identifying vulnerable plaques such as thin-cap fibroatheroma due to the limitation of the image resolution [25], stent coverage only to the vulnerable plaques might be more reasonable. Because optical coherent tomography (OCT) would detect vulnerable plaques more precisely than IVUS, especially in the culprit lesions of AMI [26, 27], OCT-guided stent coverage only to the vulnerable plaques may be a better option if possible. A prospective study is warranted to confirm whether aorto-ostial coverage is beneficial to the mild to moderate ostial stenosis 
Table II. Comparison of lesions and procedural characteristics between ostial-stent and non-stent groups

\begin{tabular}{|c|c|c|c|c|}
\hline Variable & $\begin{array}{c}\text { All } \\
(n=236)\end{array}$ & $\begin{array}{l}\text { Ostial-coverage } \\
\quad(n=52)\end{array}$ & $\begin{array}{l}\text { Non-coverage } \\
(n=184)\end{array}$ & $P$-value \\
\hline \multicolumn{5}{|l|}{ Lesions and procedural characteristics: } \\
\hline Reason for $\mathrm{PCl}$ : & & & & 0.293 \\
\hline PCI to culprit lesion of STEMI, $n(\%)$ & $45(19.1)$ & $6(11.5)$ & $39(21.2)$ & \\
\hline PCI to the culprit lesion of NSTEMI, $n(\%)$ & $41(17.4)$ & $10(24.4)$ & $31(16.8)$ & \\
\hline PCI to non-acute myocardial infarction lesions, $n(\%)$ & $150(63.6)$ & $36(69.2)$ & $114(62.0)$ & \\
\hline ACC/AHA type B2/C, $n$ (\%) & $155(65.7)$ & $41(78.8)$ & $114(62.0)$ & 0.24 \\
\hline \multicolumn{5}{|l|}{ QCA for target lesions: } \\
\hline Reference diameter [mm] & $2.47(2.0-2.99)$ & $2.47(1.87-2.96)$ & $2.47(2.01-2.99)$ & 0.621 \\
\hline Minimum lumen diameter [mm] & $0.68(0.35-0.95)$ & $0.68(0-1.11)$ & $0.68(0.40-0.94)$ & 0.581 \\
\hline Lesion length [mm] & $17.8(11.3-35.9)$ & $32.1(13.1-42.7)$ & $17.2(10.3-31.1)$ & 0.012 \\
\hline Percent diameter stenosis (\%) & $72.2(62.1-84.0)$ & $72.8(58.5-100)$ & $72.2(62.5-83.2)$ & 0.741 \\
\hline \multicolumn{5}{|l|}{ QCA for RCA ostium: } \\
\hline Minimum lumen diameter [mm] & $3.11(2.58-3.67)$ & $2.98(2.38-3.55)$ & $3.14(2.62-3.75)$ & 0.114 \\
\hline Percent diameter stenosis (\%) & $8.3(4.0-14.5)$ & $7.3(3.8-14.2)$ & $8.9(4.4-14.5)$ & 0.309 \\
\hline Chronic total occlusion, $n$ (\%) & $28(11.9)$ & $12(23.1)$ & $16(8.7)$ & 0.008 \\
\hline Continuous ostial plaque detected by IVUS, $n(\%)$ & $123(52.1)$ & $44(84.6)$ & $79(52.9)$ & $<0.001$ \\
\hline Continuous ostial plaque detected by angiography, $n(\%)$ & $107(45.3)$ & $43(82.7)$ & $64(34.8)$ & $<0.001$ \\
\hline Coronary injury in RCA ostium, $n(\%)$ & 0 & 0 & 0 & \\
\hline IVUS Grey-scale plaque type: & $(n=231)$ & $(n=52)$ & $(n=179)$ & 0.271 \\
\hline Hypo-echoic, $n$ (\%) & $119(51.5)$ & $24(46.2)$ & $95(53.1)$ & \\
\hline Hyper non-calcification, $n$ (\%) & $16(6.9)$ & $2(3.8)$ & $14(7.8)$ & \\
\hline Hyper calcification, $n$ (\%) & 39 (16.9) & $13(25.0)$ & $26(14.5)$ & \\
\hline Mixed, $n(\%)$ & $57(24.7)$ & $13(25.0)$ & $44(24.6)$ & \\
\hline IVUS measurement of the culprit lesion: & $(n=231)$ & $(n=52)$ & $(n=179)$ & \\
\hline Vessel diameter [mm] & $4.05(3.60-4.60)$ & $3.98(3.60-4.60)$ & $4.10(3.60-4.60)$ & 0.998 \\
\hline Vessel area $\left[\mathrm{mm}^{2}\right]$ & $13.2(10.3-16.8)$ & $13.1(10.3-16.9)$ & $13.2(10.2-16.8)$ & 0.974 \\
\hline Lumen area $\left[\mathrm{mm}^{2}\right]$ & $1.98(1.55-2.47)$ & $1.85(1.51-2.46)$ & $2.02(1.55-2.47)$ & 0.47 \\
\hline Plaque area $\left[\mathrm{mm}^{2}\right]$ & $10.9(8.3-14.5)$ & $10.6(8.4-14.1)$ & $11.1(8.2-14.7)$ & 0.825 \\
\hline Plaque area/external elastic membrane area (\%) & $84.4(79.8-88.1)$ & $85.0(80.0-87.9)$ & $84.2(79.8-88.2)$ & 0.746 \\
\hline \multicolumn{5}{|l|}{ Procedural characteristics: } \\
\hline Guiding catheter size: & & & & 0.023 \\
\hline $6 \mathrm{Fr}, n(\%)$ & $134(56.8)$ & $21(40.4)$ & $113(61.4)$ & \\
\hline $7 \mathrm{Fr}, n(\%)$ & $94(39.8)$ & $28(53.8)$ & $66(35.9)$ & \\
\hline $8 \mathrm{Fr}, n(\%)$ & $8(3.4)$ & $3(5.8)$ & $5(2.7)$ & \\
\hline Guiding catheter type: & & & & 0.019 \\
\hline Judkins right, $n(\%)$ & $49(20.8)$ & $18(34.6)$ & $31(16.8)$ & \\
\hline Amplatz left, $n(\%)$ & $186(78.8)$ & $34(65.4)$ & $152(82.6)$ & \\
\hline $\mathrm{IM}, n(\%)$ & $1(0.4)$ & $0(0)$ & $1(0.5)$ & \\
\hline Guiding catheter with side hole, $n(\%)$ & $236(100)$ & $52(100)$ & $183(100)$ & - \\
\hline Intra-aortic balloon pump support, $n$ (\%) & $7(3.0)$ & $3(5.8)$ & $4(2.2)$ & 0.182 \\
\hline Percutaneous cardiopulmonary support, $n(\%)$ & $6(2.5)$ & $1(1.9)$ & $5(2.7)$ & 1.0 \\
\hline Rotational atherectomy, $n$ (\%) & 28 (11.9) & $12(23.1)$ & $16(8.7)$ & 0.008 \\
\hline Mean stent diameter [mm] & $2.88(2.50-3.0)$ & $3.0(2.69-3.22)$ & $2.75(2.50-3.0)$ & 0.003 \\
\hline Stent length $[\mathrm{mm}]$ & $28.0(18.0-38.0)$ & $38.0(30.0-60.8)$ & $24.0(18.0-38.0)$ & $<0.001$ \\
\hline Stent number & $1.0(1.0-1.0)$ & $1.0(1.0-2.0)$ & $1.0(1.0-1.0)$ & $<0.001$ \\
\hline
\end{tabular}

Data are expressed as the median (interquartile range) or number (percentage). Student'st-test or Mann-Whitney U test was used for continuous variables, and $\chi^{2}$ test was used for categorical variables. PCI - percutaneous coronary intervention, STEMI-ST-segment elevation myocardial infarction, NSTEMI - non-ST-segment elevation myocardial infarction, RCA - right coronary artery. 
Table III. Multivariate logistic regression analysis to find factors associated with ostial stent implantation

\begin{tabular}{lccc}
\hline \multicolumn{2}{l}{ Dependent variable: Ostial stent coverage } & & \\
\hline Independent variables & Odds ratio & 95\% confidence interval & $P$-value \\
\hline Lesion length [mm] & 1.007 & $0.992-1.022$ & 0.384 \\
\hline Chronic total occlusion & 1.947 & $0.746-5.079$ & 0.173 \\
\hline Rotational atherectomy & 2.065 & $0.768-5.554$ & 0.151 \\
\hline Continuous ostial plaque detected by IVUS & 5.398 & $2.322-12.553$ & $<0.001$ \\
\hline Guiding catheter size 7-8Fr (vs. 6Fr) & 1.166 & $0.522-2.604$ & 0.708 \\
\hline Guiding catheter type AL (vs. others) & 0.403 & $0.187-0.868$ & 0.020
\end{tabular}

All variables were simultaneously adjusted in a single step.

when $\mathrm{PCl}$ to severely narrowed, non-ostial RCA lesions is planned.

First, because this study was a single-centre, retrospective study, there is a risk of selection bias. Second, our study population did not include any cases that had coronary artery injury caused by the guide catheter, partly because our study sample size was not sufficiently large to have such cases. Third, there were no strict instructions regarding aorto-ostial stent coverage during the study period in our catheter laboratory. Thus, ostial stent coverage was influenced by the discretion of each interventional cardiologist. Although the use of rotational atherectomy is known to be associated with extended stenting, it was difficult to determine whether the procedure itself or rather the plaque composition (calcium) played the central role in the extended stenting in this retrospective study. When we checked continuous ostial plaque in IVUS, we tried to include minor plaques seen in IVUS. However, some minor plaques might be missed because of the limitation of the IVUS resolution.

\section{Conclusions}

Continuous ostial plaque detected by IVUS was significantly associated with ostial stent coverage to mild to moderate stenosis when $\mathrm{PCl}$ to severely narrowed non-ostial RCA lesions were performed. The use of IVUS may enhance the safety but may increase the total stent length in $\mathrm{PCl}$ to the RCA.

\section{Acknowledgments}

The authors acknowledge all staff in the catheter laboratory in Jichi Medical University, and Saitama Medical Centre for their technical support in this study.

\section{Conflict of interest}

Dr. Sakakura has received speaking honoraria from Abbott Vascular, Boston Scientific, Medtronic Cardiovascular, Terumo, OrbusNeich, Japan Lifeline, Kaneka, and NIPRO; he has served as a proctor for Rotablator for Boston
Scientific, and he has served as a consultant for Abbott Vascular and Boston Scientific. Dr. Jinnouchi has received speaking honoraria from Abbott Vascular. Prof. Fujita has served as a consultant for Mehergen Group Holdings, Inc. Other authors have no conflicts of interest to declare.

\section{References}

1. Hiraide T, Sawano M, Shiraishi Y, et al. Impact of catheter-induced iatrogenic coronary artery dissection with or without postprocedural flow impairment: a report from a Japanese multicenter percutaneous coronary intervention registry. PLoS One 2018; 13: e0204333.

2. Núñez-Gil IJ, Bautista D, Cerrato E, et al. Incidence, management, and immediate- and long-term outcomes after iatrogenic aortic dissection during diagnostic or interventional coronary procedures. Circulation 2015; 131: 2114-9.

3. Gürdal A, Yıldız SS, Kılıçkesmez K. Catheter induced aortocoronary dissection during percutaneous coronary intervention: successful aortoostial stenting. Turk Kardiyoloji Dernegi Arsivi 2018; 46: 57-60.

4. Sakamoto H, Ishikawa T, Mutoh M, et al. Angiographic and clinical outcomes after sirolimus-eluting stent implantation to de novo ostial lesion of the right coronary artery: a retrospective study. Circ J 2008; 72: 880-5.

5. Watanabe Y, Takagi K, Naganuma T, Nakamura S. Comparison of early- and new-generation drug-eluting stent implantations for ostial right coronary artery lesions. Cardiovasc Ther 2017; 35. DOI: 10.1111/1755-5922.12247.

6. Thygesen K, Alpert JS, Jaffe AS, et al. Fourth Universal Definition of Myocardial Infarction (2018). J Am Coll Cardiol 2018; 72 : 2231-64.

7. Sawano M, Yamaji K, Kohsaka S, et al. Contemporary use and trends in percutaneous coronary intervention in Japan: an outline of the J-PCI registry. Cardiovasc Interv Ther 2020; 35: 218-26.

8. O'Gara PT, Kushner FG, Ascheim DD, et al. 2013 ACCF/AHA guideline for the management of ST-elevation myocardial infarction: executive summary: a report of the American College of Cardiology Foundation/American Heart Association Task Force on Practice Guidelines. J Am Coll Cardiol 2013; 61: 485-510.

9. Seguchi M, Sakakura K, Yamamoto K, et al. Comparison of in-hospital clinical outcomes of acute myocardial infarction between nonagenarians and octogenarians. Int Heart J 2020; 61: 7-14. 
10. Seguchi M, Sakakura K, Tsukui T, et al. Determinants of in-hospital death among the very elderly with acute myocardial infarction. Int Heart J 2020; 61: 879-87.

11. Watanabe Y, Sakakura K, Taniguchi Y, et al. Determinants of slow flow in percutaneous coronary intervention to the culprit lesion of non-ST elevation myocardial infarction. Int Heart J 2018; 59: 1237-45.

12. Sawano S, Sakakura K, Yamamoto K, et al. Further validation of a novel acute myocardial infarction risk stratification (nARS) system for patients with acute myocardial infarction. Int Heart J 2020; 61: 463-9.

13. Yoshida H, Sakakura K, Yamamoto K, et al. Comparison of in-hospital death following ST-elevation myocardial infarction between secondary emergency and tertiary emergency. Cardiovasc Interv Ther 2020. DOI:10.1007/s12928-020-00698-8.

14. Matsuo S, Imai E, Horio M, et al. Revised equations for estimated GFR from serum creatinine in Japan. Am J Kidney Dis 2009; 53: 982-92.

15. Yamamoto K, Sakakura K, Tsukui T, et al. Clinical factors associated with slow flow in left main coronary artery-acute coronary syndrome without cardiogenic shock. Cardiovasc Interv Ther 2020. doi: 10.1007/s12928-020-00717-8.

16. Sakakura K, Taniguchi Y, Yamamoto K, et al. Comparison of complications with a $1.25-\mathrm{mm}$ versus a $1.5-\mathrm{mm}$ burr for severely calcified lesions that could not be crossed by an intravascular ultrasound catheter. Cardiovasc Interv Ther 2020; 35: 227-33.

17. Mizuno Y, Sakakura K, Yamamoto K, et al. Determinants of periprocedural myocardial infarction in current elective percutaneous coronary interventions. Int Heart J 2020; 61: 1121-8.

18. Räber L, Mintz GS, Koskinas KC, et al. Clinical use of intracoronary imaging. Part 1: guidance and optimization of coronary interventions. An expert consensus document of the European Association of Percutaneous Cardiovascular Interventions. Eur Heart J 2018; 39: 3281-300.

19. Sakakura K, Wada H, Taniguchi Y, et al. Intravascular ultrasound-guided coronary stenting without contrast medium for the treatment of catheter-induced aortocoronary dissection. Cardiovasc Interv Ther 2013; 28: 71-5.

20. Yamamoto K, Sakakura K, Adachi Y, et al. Comparison of midterm clinical outcomes between "complete full-metal jacket strategy" versus "incomplete full-metal jacket strategy" for diffuse right coronary artery stenosis with drug-eluting stents. J Cardiol 2017; 69: 823-9.

21. Yano H, Horinaka S, Ishimitsu T. Impact of everolimus-eluting stent length on long-term clinical outcomes of percutaneous coronary intervention. J Cardiol 2018; 71: 444-51.

22. Claessen BE, Smits PC, Kereiakes DJ, et al. Impact of lesion length and vessel size on clinical outcomes after percutaneous coronary intervention with everolimus- versus paclitaxel-eluting stents pooled analysis from the SPIRIT (Clinical Evaluation of the XIENCE V Everolimus Eluting Coronary Stent System) and COMPARE (Second-generation everolimus-eluting and paclitaxel-eluting stents in real-life practice) Randomized Trials. JACC Cardiovasc Interv 2011; 4: 1209-15.

23. Baumann S, Behnes $M$, Sartorius B, et al. Follow-up of iatrogenic aorto-coronary "Dunning" dissections by cardiac computed tomography imaging. BMC Med Imaging 2017; 17: 64.

24. Ramasamy A, Bajaj R, Jones DA, et al. latrogenic catheter-induced ostial coronary artery dissections: prevalence, management, and mortality from a cohort of 55,968 patients over 10 years. Catheter Cardiovasc Interv 2020. DOI: https://doi. org/10.1002/ccd.29382.
25. Nakano $M$, Yahagi K, Yamamoto $H$, et al. Additive value of integrated backscatter IVUS for detection of vulnerable plaque by optical frequency domain imaging: an ex vivo autopsy study of human coronary arteries. JACC Cardiovasc Imaging 2016; 9 : 163-72.

26. Kurogi K, Ishii M, Yamamoto N, et al. Optical coherence tomography-guided percutaneous coronary intervention: a review of current clinical applications. Cardiovasc Interv Ther 2021; 36: 169-77.

27. Mrevlje B, Kleczyński P, Kranjec I, et al. Optical coherence tomography versus intravascular ultrasound for culprit lesion assessment in patients with acute myocardial infarction. Adv Interv Cardiol 2020; 16: 145-52. 